\title{
Chemical and Isotope Studies of Zakher Lake and Its Possible Risk on the Geoenvironment, Al Ain, United Arab Emirates
}

\author{
${ }^{* 1}$ Saber Hussein, ${ }^{1}$ Hasan Arman, ${ }^{1}$ Dalal Al Shamsi, ${ }^{1}$ Ahmed Murad, ${ }^{1}$ Ala Aldahan \\ ${ }^{1}$ College of Science, Department of Geology, United Arab University, Al Ain, United Arab Emirates
}

\begin{abstract}
This study concerns the occurrence of pollutants in Zakher Lake, Al Ain, UAE, which are relevant to the water supply and impact on ecosystem. Lake water and sediment samples were collected from the lake and were analyzed for different chemical and physical properties. In-situ measurements of temperature, pH, EC and TDS and Rn-222 activity were carried out using a WTW-COND-330I and RAD7 instrument with errors of $<5 \%$. The analyses of trace and major elements were performed using inductively coupled plasma optical emission spectroscopy (ICP-OES) Varian 715 with errors $<5 \%$. The results reveal high concentrations of $\mathrm{Na}, \mathrm{K}, \mathrm{Mg}$ and $\mathrm{Ca}, \mathrm{Fe}, \mathrm{Mn}, \mathrm{Al}, \mathrm{Sr}, \mathrm{Ba}$ and $\mathrm{Pb}$ in water samples of the lake, which are higher than permissible limits for drinking and irrigation. Variable concentrations of these elements were found in the sediment samples. In addition, radon isotope ( $\mathrm{Rn}-222)$ data in the lake water indicate activity values below the detection limit of the instrument. The high concentrations of major and trace elements support the idea that the water is polluted. The sources of water to the lake are considered mainly anthropogenic due to the relatively high activity of Rn-222 in surrounding groundwater wells that is not detected in the lake water. Consequently, the lake water is not suitable for drinking, domestic or irrigation purposes and may be considered as a source of environmental hazard in the area.
\end{abstract}

Key words: Zaher Lake, pollution, environment, risk, UAE

\section{Introduction}

Zakher Lake is one of the recent surface water features that occurred in $\mathrm{Al}$ Ain area and lies at the north western of Hafit Mountain with about $12 \mathrm{~km}$ in a sand dune zone. The lake is surrounded by farming, industrial as well as a new urban district of $\mathrm{Al}$ Ain City (Figure 1). Compost factory and the Al Ain wastewater treatment station are located near by the lake. The dumped water from all of these land use around the lake as well as the water from the dewatering projects during the constructions of the infrastructure may take pathway to the low land areas where the lake is located. The lake appeared in 2003 and has expand in its form (Figure 1) in 2016 and since that has been shrinking in size with changes in water level and quality as well as its own ecosystem with birds, plants and fish [1] and [2]. Despite the interesting situation of Zakher lake, there were no data on water quality, sources and interaction between the sediments and the lake water. Accordingly, this study aims to investigate details of chemical components of both water and sediments of the lake and the link between water sources to the lake and pollution.

\footnotetext{
${ }^{*}$ Corresponding author: Address: College of Science, Department of Geology, United Arab Emirates University, Al Ain, UNITED ARAB EMIRATES, E-mail address: S_Hussein@uaeu.ac.ae, Phone: +97137136365
} 


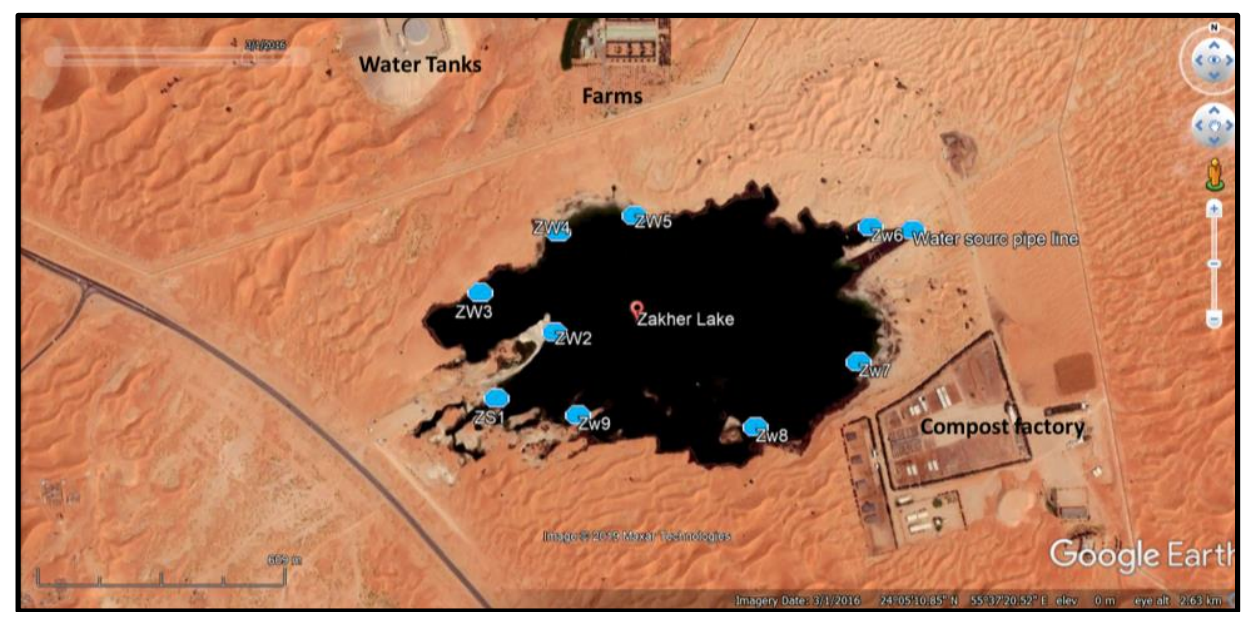

Figure 1. Location of the sampling sites in the lake, surrounded by industrial and farming areas

\section{Materials and Method}

Water and sediment samples were collected from accessible sites around the lake (Figures 1 and 2). The water samples collected from each site were stored in icebox and refrigerated at $4^{\circ} \mathrm{C}$ in the lab until analyses. For major cations and trace element analyses, a few drops of concentrated nitric acid $(65 \%)$ was added into water samples collected in 1-liter plastic (HDPE wide mouth) bottle in the field after sampling. Water samples for Rn-222 measurement were collected in $10 \mathrm{ml}$ low diffusion LSC vial and measured in-situ using RAD7 instrument. Temperature, $\mathrm{pH}, \mathrm{EC}$ and TDS were measured using a WTW-COND-330I instrument with an error of $<5 \%$. The sediment samples were collected parallel to the water samples, stored in plastic bags, and transported to the hydrogeology laboratory in United Arab Emirate University (UAEU), Geology Department for analysis. The analyses of cations and trace elements were conducted using inductively coupled plasma optical emission spectroscopy (ICP-OES) Varian 715 instrument. Water sample was directly injected into nebulizer and spectral analysis of each element was standardized using a multi-element standard solution GSC-CAL-8 provided by Inorganic Ventures (Figure 3). The analytical error of all samples is $<5 \%$, while the detection limit was in the range of 0.001 to 0.017 $\mathrm{mg} / \mathrm{L}$. The analysis results of the water samples for major and trace elements of Zakher lake water compared with the local and international permissible limits are shown in Table 1.

\section{Results}

The in-situ measurements of physiochemical parameters of the lake's water are shown in Table 1. The results reveal extremely high Total Dissolved Solids (TDS), which varies between 5083 to $12400 \mathrm{mg} / \mathrm{L}$ and exhibits saline water quality compared with the groundwater quality in the area (TDS about $2000 \mathrm{mg} / \mathrm{L}$ ). The variation in major cations including $\mathrm{K}, \mathrm{Na}, \mathrm{Mg}$ and $\mathrm{Ca}$ indicates high concentration with average values of $140,1757,525,660 \mathrm{mg} / \mathrm{L}$, respectively. Concentrations of K, $\mathrm{Na}, \mathrm{Mg}$ and $\mathrm{Ca}$ in the sediments of the lake reveal values at $699,2412,12347$ and $111112 \mathrm{mg} / \mathrm{kg}$ respectively. The cationic composition order exhibits $\mathrm{Na}>\mathrm{Ca}>\mathrm{Mg}>\mathrm{K}$ in the water samples while it 
is $\mathrm{Ca}>\mathrm{Mg}>\mathrm{Na}>\mathrm{K} \mathrm{mg} / \mathrm{kg}$ in the sediment samples. The trace elements indicate low concentrations except $\mathrm{Sr}$ which shows relatively high value (Table 1). Compared with the permissible limits for drinking water of the World Health Organization (WHO) and Environmental Agency of Abu Dhabi, all the major cations and TDS exceed the limit values [3-5].
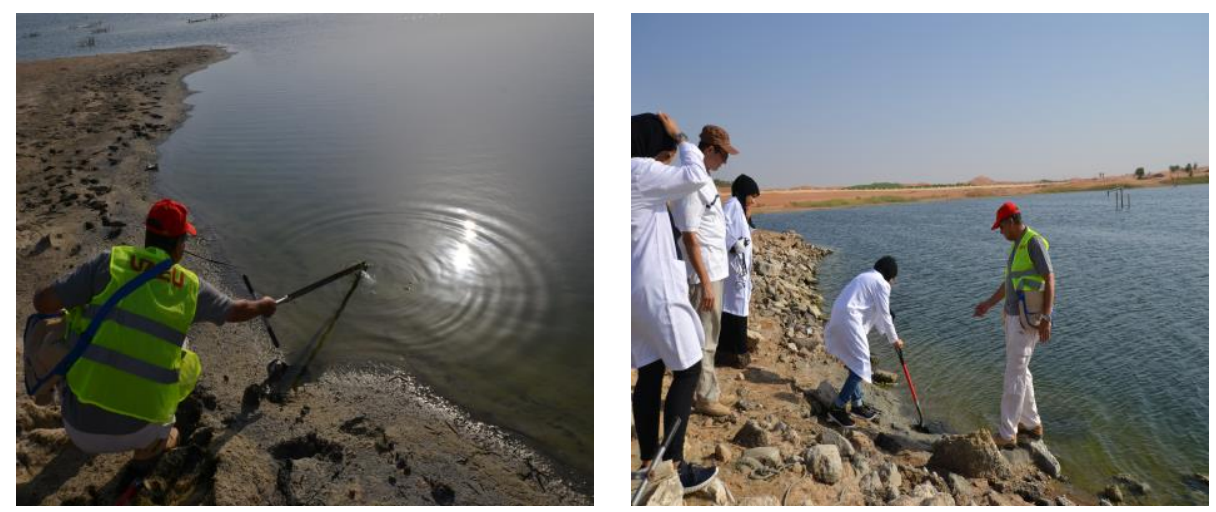

Figure 2. Water and soil sampling campaign
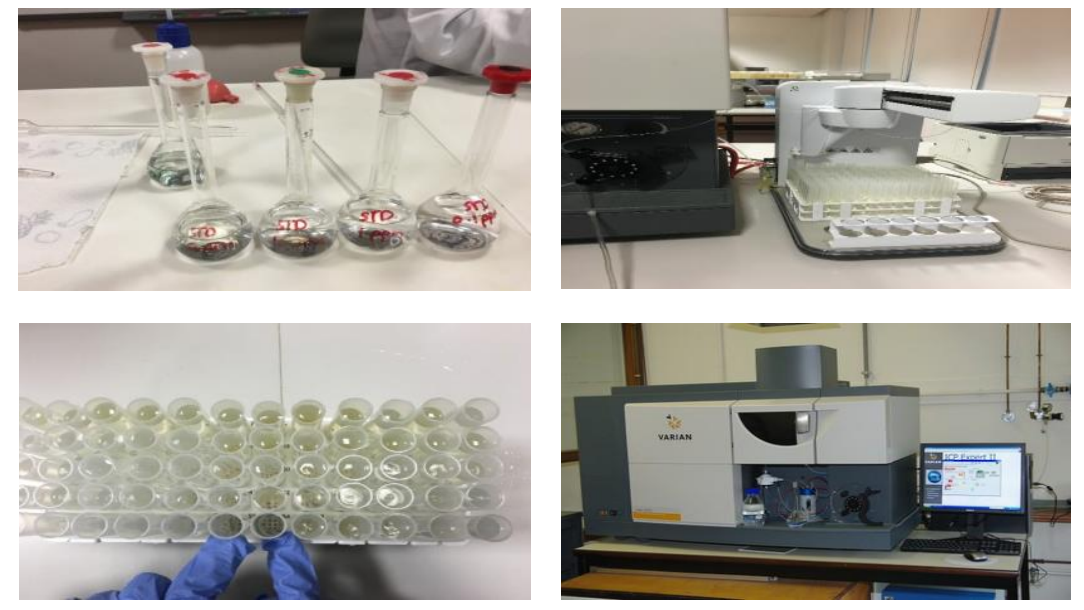

Figure 3. Laboratory preparation and analyses of the collected samples

\section{Discussion}

The chemical results of the lake water show about 3-5 folds higher concentrations of TDS and major cations than the groundwater in the surrounding area. These features suggest two possibilities for this water quality in the lake. The first possibility is enhanced concentration through evaporation, which is further intensified by leaching from the sediments. The second possibility is supply of water to the lake that has the composition analyzed. Sources of water supply to the lake are expected to be shallow running water, which is higher in level than the conventional groundwater level in the area. This is because the lake level lies at about 10 meters above groundwater level and there is no surface water supply (stream runoff). The most plausible sources that can supply water to the lake are shallow leakages from industrial treatment water, damaged sewage pipelines and infiltration from irrigation water. All these anthropogenic activities are 
located close to the lake basin (Figure 1). Another evidence for excluding groundwater as a supply source for the lake is the depletion of $\mathrm{Rn}-222$ from the lake water while the isotope occurs at relatively high activity $20 \mathrm{~Bq} / \mathrm{L}$ in the groundwater wells around the lake. The exclusion of groundwater as feeding source is also supported by the shrinking area of the lake during two years without noticeable changes in the groundwater level. At the same time, the sewage water treatment station was allocated far away from the lake and thereby reduced leakage from the existing pipelines.

Knowing that sources of water supply to the lake are dominantly anthropogenic, it is expected that the chemical composition of the lake water was development through a coupled interaction of sediment leaching and evaporation processes. The excessive concentrations of $\mathrm{K}$ and $\mathrm{Na}$ can be attributed to irrigation water and reaction of sewage water with the feldspars rich dune sediments that are deposited in the lake. Calcite and dolomite are also common minerals in the sediments that are partially affected by the outcropping carbonate rich bedrocks in the region. Apparently, there has been little contribution of the chemical interaction processes on the trace elements concentration in the lake water. This may relate to the relatively low concentration of trace elements in carbonate minerals that is also supported by the high $\mathrm{Sr}$ values.

Table 1. Chemical composition of major and trace elements of water compared with local and international permissible limits for drinking.

\begin{tabular}{lcccc}
\hline \multicolumn{1}{c}{ Component } & WHO-2004 & WHO-2012 & EAD-2006 & Zakher Lake \\
\hline Total Dissolved Solids TDS) (mg/L) & 1000 & 500 & $100-1000$ & $5083-12400$ \\
Calcium (Ca) (mg/L) & $\mathrm{NE}$ & $\mathrm{NE}$ & $\mathrm{NE}$ & $251-746$ \\
Magnesium (Mg) mg/L) & $\mathrm{NE}$ & $\mathrm{NE}$ & 30 & $359-549$ \\
Iron (Fe) (mg/L) & 0.3 & 0.3 & 0.2 & $0.01-0.21$ \\
Manganese (Mn) (mg/L) & 0.4 & 0.05 & 0.4 & $0.01-0.05$ \\
Aluminium (Al) (mg/L) & 0.2 & $0.05-0.2$ & 0.2 & $0.05-0.16$ \\
Potassium (K) (mg/L) & $\mathrm{NE}$ & $\mathrm{NE}$ & 12 & $65-152$ \\
Sodium (Na) (mg/L) & 200 & $\mathrm{NE}$ & 150 & $1120-2014$ \\
Strontium (Sr) (mg/L) & $\mathrm{NE}$ & $\mathrm{NE}$ & $\mathrm{NE}$ & $15-30$ \\
Barium $\mathrm{Ba}(\mathrm{mg} / \mathrm{L})$ & 0.7 & 2 & 0.7 & $0.05-0.07$ \\
Lead, $\mathrm{Pb}(\mathrm{mg} / \mathrm{L})$ & 0.01 & 0.015 & 0.01 & $0.01-0.06$ \\
\hline
\end{tabular}

\section{Conclusions}

The results show high concentrations of TDS, $\mathrm{K}, \mathrm{Na}, \mathrm{Mg}$ and $\mathrm{Ca}$ in water samples of Zakher lake that exceed the permissible limits for drinking while the trace elements indicate low concentrations except Sr, which shows relatively high value. The observable high concentrations of major elements and TDS suggest that the lake water is contaminated. Sources of water supply to the lake are linked to anthropogenic activities including industrial, irrigation and sewage water. In addition, depletion of Rn-222 from the lake water excludes groundwater system in the region as water supply to the lake. On the contrary, the polluted water of the lake may become a source of 
environmental hazard to the groundwater aquifer if there is possibility of infiltration downward. Eventually, the use of the lake water for direct household (washing, showering, gardening, etc.) and recreation (swimming, fish farming, etc.) and cannot be recommended.

\section{Acknowledgements}

The authors wish to express their gratitude to undergraduate students and technicians at the department of geology for their help at different stages of the research. Of course, this research could not be completed without the generous support of the United Arab Emirates University and department of geology.

\section{References}

[1] Zakher Lake. Uaebirding.com. Retrieved 2 December 2016, from http://www.uaebirding.com/sites/al_ain/zakherlake.html, 2016.

[2] Dawit T. Ghebreyesus, Marouane Temimi, Ali Fares, and Haimanote K. Bayabil. A multisatellite approach for water storage monitoring in an arid watershed Geosciences 2016; 6, 33, 114, doi:10.3390/geosciences6030033.

[3] World Health Organization (WHO). 2004. Volume 1: Recommendations, 2004.

[4] World Health Organization (WHO), 2012. Guidelines for Drinking-water Quality, Fourth

Edition, 541p. http://www.who.int/water_sanitation_health/dwq/guidelines/en/

[5] The Regulation and Supervision Bureau for the Water, Wastewater and Electricity Sector in the Emirate of Abu Dhabi; Water Quality Regulation Rev. (3.), CD/R01/009, 28 September 2006. 